\title{
EL NUEVO CONSTITUCIONALISMO MULTICULTURAL: ¿REFORMA O REVOLUCIÓN? REFLEXIONANDO ACERCA DE LOS LÍMITES DEL CONSTITUCIONALISMO
}

\author{
THE NEW MULTICULTURAL CONSTITUTIONALISM: \\ REFORM OR REVOLUTION? REFLECTING ON THE LIMITS OF \\ CONSTITUTIONALISM
}

Albert Noguera Fernández;*)

Resumen: La victoria electoral en algunos de los países andinos de proyectos políticos de izquierda transformadora, y de nuevos procesos constituyentes, especialmente en Venezuela, Bolivia y Ecuador, ha despertado una reacción entusiasta en los observadores progresistas. El discurso o fraseología revolucionaria y las transformaciones impulsadas (nacionalización de los sectores productivos estratégicos, reformulación de la división en los tres poderes clásicos del Estado, creación de nuevas formas de participación ciudadana, la garantía efectiva de los derechos económicos y sociales, la reconstrucción de la Constitución económica incluido el concepto de propiedad privada, etc.), han puesto sobre la mesa un debate que parecía cerrado desde la derrota de la Unidad Popular del Presidente Allende, el de la "transición pacífica al socialismo" o hacia un Estado y un Derecho nuevo.

El nuevo constitucionalismo latinoamericano está suponiendo un proceso de construcción del llamado socialismo del siglo XXI, y de un nuevo Estado y Derecho, que ahora son puestos en cuestión. Entonces, ¿nos encontramos ante una auténtica revolución de la que está emergiendo una nueva forma de Estado y de Derecho no liberal?, o bien, ¿estamos ante una simple evolución, ampliación y especificación de los derechos liberales y de un constitucionalismo liberal de tercera generación?

(*) Licenciado y Doctor en Derecho. Licenciado en Ciencias Políticas y de la Administración. Profesor de Derecho Constitucional en la Universidad de Extremadura (España). 
Palabras clave: Constitucionalismo, revolución, socialismo del siglo XXI, derechos liberales, Latinoamérica.

Abstract: The electoral victory in some of the Andean countries of left political projects, and new constitutional processes, especially in Venezuela, Bolivia and Ecuador, has attracted an enthusiastic reaction in progressive observers. The speech or revolutionary phraseology and driven transformations (nationalization of strategic productive sectors, reformulation of the division into the three traditional branches of government, creating new forms of citizen participation, effective guarantee of economic and social rights, rebuilding economic Constitution included the concept of private property, etc.), they have put on the table a debate that seemed closed since the defeat of the Popular Unity of President Allende, the "peaceful transition to socialism" or about a State and a new law.

The new Latin American constitutionalism is assuming a process called construction of socialism of the XXI century, and a new State and law, which are now called into question. Therefore, are we facing a real revolution in which is emerging a new form of State and an illiberal law? or are we facing a simple evolution, extension and specification of liberal rights and liberal third generation constitutionalism?

Key words: Constitutionalism, revolution, socialism of the XXI century, liberal rights, Latin America.

Tabla de contenido: -1. Introducción. -2. ¿Qué es el Derecho Nuevo? -3. ¿El neoconstitucionalismo multicultural andino como derecho nuevo? 3.1. El modelo multi-civilizatorio o multi-organizativo (comunitario) de estado como ilusión desvanecida. -4. El constitucionalismo multicultural como constitucionalismo liberal de tercera generación. 4.1. La contradicción libertad-igualdad y la contradicción política. 4.1.1. La ficción de la redistribución de la riqueza, expresada en el constitucionalismo social. 4.1.2. La ficción de la aceptación de la voluntad política del pueblo como determinante de la acción de gobierno, expresada en la democracia representativa. 4.2. La contradicción cultural. 4.2.1. La ficción de la igualdad cultural, expresada en el constitucionalismo multicultural. -5. Los aportes del constitucionalismo liberal de tercera generación. 5.1. El tratamiento constitucional de los derechos: reconocimiento, igual jerarquía, indivisibilidad y justiciabilidad. .Referencias. 


\section{Introducción}

La victoria electoral en algunos de los países andinos, en un contexto de crisis del Estado neoliberal, de proyectos políticos de izquierda transformadora, así como los nuevos procesos constituyentes impulsados por estos, especialmente en Venezuela, Bolivia y Ecuador, ha despertado, en los últimos años, una reacción entusiasta en los observadores progresistas de todo el mundo.

El discurso o fraseología revolucionaria usada por los dirigentes de estos procesos de cambio político y las transformaciones impulsadas (nacionalización de los sectores productivos estratégicos, reformulación de la división en los tres poderes clásicos del Estado, creación de nuevas formas de participación ciudadana directa en la política, la garantía efectiva de los derechos económicos y sociales, la reconstrucción de la Constitución económica incluido el concepto de propiedad privada, etc.), han puesto sobre la mesa, de nuevo, un debate que parecía cerrado desde la derrota de la Unidad Popular del Presidente Allende, el de la "transición pacifica al socialismo" o hacia un Estado y un Derecho nuevo.

Si bien han sido diversas las voces que han afirmado que el nuevo constitucionalismo latinoamericano está suponiendo, a partir de una revisión de las categorías tradicionales de la izquierda, un proceso de construcción de un nuevo socialismo, el llamado socialismo del siglo XXI, y, por tanto, de un nuevo Estado y Derecho, también son muchas las voces que lo ponen en cuestión. Entonces, ¿̇nos encontramos ante una auténtica revolución de la que está emergiendo una nueva forma de Estado y de Derecho no liberal?, o bien, ¿estamos ante una simple evolución, ampliación $y$ especificación de los derechos liberales $v$, por tanto, ante un constitucionalismo liberal de tercera generación? Esta será la pregunta que intentaré responder en este trabajo.

\section{2. ¿Qué es el Derecho Nuevo?}

Lo primero que hay que hacer para intentar ver si el nuevo constitucionalismo multicultural latinoamericano constituye una auténtica revolución y la creación de un Estado y un Derecho nuevo, es definir que entendemos por "Derecho nuevo".

De manera muy simplista, podríamos decir que el Derecho nuevo es aquel sistema de normas que dejarian de actuar como mecanismo vertical de dominación para pasar a actuar como mecanismo horizontal de autoorganización ciudadana.

El Derecho de raíz liberal es un mecanismo vertical de dominación, en tanto emana de instituciones estatales o supraestatales, y ejerce dominación desde dos niveles: 
- Desde el nivel físico, mediante la imposición de sanciones, como describe la teoría jurídica de la coacción (Hobbes, Austin, Kelsen, Olivecrona), la cual considera como eje central del concepto de Derecho, la aplicación de sanciones por parte del aparato coactivo.

- Y, desde el nivel subjetivo. Uno de los principios básicos de la sociología jurídica ha sido siempre la concepción del Derecho como un sistema unitario y cerrado de reglas que ordenan normativamente la totalidad de actividades vitales, sistematización que contiene, como uno de sus momentos esenciales, el intento de realizar el valor "justicia", mediante el cual se "legitima" el orden social (Ayala, F., 1947: 415-416). "Orden" $y$ "justicia" son pues, cosas que se implican recíprocamente del modo más riguroso, el Derecho organiza un "orden" y al mismo tiempo lo "justifica"(1). Se convierte en un "orden legitimo" que cumplir(2). En consecuencia, el Derecho encamina a los miembros de una sociedad concreta a la adopción de comportamientos, normas o reglas de conducta determinadas (cultura), y que el grupo considera como socialmente buenas (VIROUX, A., 1964: 26). Entonces, la dominación del Derecho se ejerce también, a parte de la coacción física, mediante la estructuración ideológica de la sociedad alrededor de un sistema cultural (legítimo).

Este actuar del Derecho como producción cultural, se materializa a través del discurso jurídico. El discurso jurídico es el que se ha encargado de normalizar y racionalizar determinados conceptos-significantes que lo que hacen es convertir la dominación en "orden legítimo". Y, ello, el discurso jurídico, lo hace a través de sus tres niveles (Ver Entelman, R., 1982: 85-109.):

1. El primero de ellos, nivel básico de formación del discurso del derecho y sobre el que pivotean los dos restantes, hace referencia a los órganos y personas autorizadas

(1) No entienda la "justicia" desde un punto vista metafísico-ontológico, es decir, obedeciendo a un esquema objetivo, la justicia como relación interna con unos valores universales e in mutables, independientes del tiempo y el espacio, ya sean valores de carácter teológico, como los que planteó Cicerón en De legibus, Agustín de Hipona en Del libre albedrío, Tomás de Aquino en su Suma Teologica, Francisco Suárez en Tractatus de legibus ac deo legislatore y Thomas Hobbes en El Leviathan, o de carácter deontológico, como los de Emmanuel Kanten Fundamentación de la metafísica de las costumbres y crítica de la razón práctica y John Rawls en Teoría de la justicia. El concepto de "justicia", es un concepto sociológico, los factores que determinan los valores interiores, la verdad o la falsedad de los juicios de justicia, dependen de las representaciones o concepciones normativas que crea una realidad social concreta. A lo largo de la historia, los grupos sociales han tendida irrefutablemente a justificar sus acciones, lo cual los ha llevado a desarrollar pautas que rigen esta justificación, y a la vez, la misma práctica de dar razones en materia de justicia ha presupuesto criterios, reglas y valores que determinan lo"justo" y lo"injusto" (Noguera Fernández, A., 2007: 100)

(2) La noción de "orden legítimo" fue ampliamente tratada por Max Weber. "El orden legítimo representa, en la teoría sociológica weberiana, la institucionalización de la conexión de sentido de las acciones sociales de los individuos. De tal forma que, -los individuos- orientan sus acciones por la representación de la existencia de un orden legitimo". Éste, el "orden legítimo", es aquel conjunto de máximas de comportamiento, cuyas representaciones operan en los individuos como modelos de conducta. En el análisis de las formas de elaboración normativa en su evolución histórica, Weber ubica, en las sociedades modernas, el "orden juridico" dentro de la categoria de "orden legítimo". (Ver: Fariñas Du/ce, M. J., 1989: 21). 
para dictar la normatividad en una sociedad. Palabras como: Constitución, Normas, Reglamentos, Decretos, Edictos, sentencias, etc.; mediante los significados que ellos reproducen, consagran un imaginario social de quiénes "están autorizados", $y$ quiénes no, para imprimir sentido jurídico a sus actos y palabras $y$, por tanto, a determinar lo que está permitido y prohibido en la sociedad.(э)

2. El segundo nivel hace referencia a los órganos y personas autorizadas para interpretar, opinar y aplicar la normatividad dictada por el primer nivel. Palabras como: abogado, juez, inspector de seguros, etc. (operadores del Derecho en general); consagran los mitos y ficciones entorno a quienes pueden, y quienes no, elaborar teorías, doctrinas y opiniones sobre el sistema juridico, así como usar y manipular las normas.

3. Finalmente, el tercer nivel del discurso jurídico, hace referencia a las interacciones entre los usuarios del Derecho. Conceptos como: contrato, acreedor, deudor, incapacitado, mayor de edad, sujeto de derecho, etc.; consagra unas y no otras formas de organización social.

El haber podido establecer, mediante estos tres niveles del discurso jurídico, una red "racional" de ficciones, mitos y creencias (construcción del imaginario social) en torno a la creación (autoridades-súbditos), aplicación y funcionamiento de la normatividad social, permite crear una construcción metonímica "autosuficiente" y "autorregulada" generadora de un "orden" que oculta el "poder". El discurso jurídico transforma el "poder" en "orden" de la manera más perfecta, sacraliza, ritualiza,

(3) Sobre la base de una conexión inconsciente con otros elementos psíquicos apriorísticos comunes -en todos los ciudadanos de una misma cultura- ("sin conocimiento dado como punto de partida, tampoco hay conocimiento alguno como continu ación. (...) No puede valer ningún conacimiento como dado sin más de antemano" (Husserl, E., 1989: 43). Por tanto, el punto de partida para ver el "modo de composición" de los objetos en la conciencia, deben ser unos elementos psíquicos com unes a priori. Pero, ¿cómo se forma este a priori que actúa de mecanismo psíquico de enlace inmediato por el que un objeto llega a ser?. Este a priori no es más que la lógica y las estructuras lógicas son correlatos de vivencias. "El individuo no constituye caprichosamente las estructuras lógicas, sino que las constituye al efectuar precisamente las operaciones a que ellas pertenecen (adecuadas) y que son los presupuestos de ellas" (Funke, 1991: 71). La práctica ritual opera unas regularidades objetivas sobreentendidas a las que se enlazan los objetos-acciones para ser "comprendidos". No hay unidad de sentido y significación sin una vivencia. El hecho psíquico que significa el objeto: 1. se da a sí mismo por medio de las vivencias a elementos originarios que se exponen en él y a la vez, 2. están en él dadas camo "sienda" evidentes. Consecuentemente, se produce aquí un doble movimiento dialéctico de irradiación de sentido, el denominado efecto del doble espejo: 1) la vivencia-lógica tomada originaria mente como enlace otorga un sentido develador del objeto (el objeto es su correlato); y al mismo tiempo, 2) el objeto, una vez constituido, remite -"confirma" o "reasegura"- mediante su en-sí, a la evidencia-lógica de la cual se reveló, reafirmándola y continuando ésta siendo válida como síntesis-conexión en "captaciones" posteriores (Shrödinger, E., 1958: 52). "La evidencia originaria no es un simple estado vivido que huye. Como donación del objeto ello crea un hábito y lleva en si, a priori, la posibilidad de poder ser nuevamente efectuada. A través de la multiplicidad indefinida de los modos de donación el pensador dispondrá siempre de posibilidades de regresar a los actos -vivencias- originariamente donadores" (Desanti, J.T, 1970: 86). En este sentido, no podemos considerar a las palabras como entidades "inertes" o "petrifica das", sino como objetivaciones de sentido que reproducen constantemente, mediante la evidencia, unas vivencias o lógica social. La reproducción del orden social se instaura en la objetividad misma que mediante "ciclos continuos de consogroción de evidencios", reà lizà su función de "sujeción". 
resignifica cada acto, cada palabra, y así los distancia de la violencia original. Crea una cierta organización de lo simbólico y un peculiar imaginario social.

Partiendo de esta base, un Derecho nuevo implicaría una reconfiguración de cada uno de estos tres niveles del discurso jurídico:

1. El primero, mediante la reordenación del espacio público participativo en el contexto de las nuevas formas de organización y participación social, lo que conllevaría la redefinición de un nuevo "sujeto de derecho" creador de una nueva mentalidad y cultura jurídico-política (sustitución del tradicional sujeto individual abstracto liberal por nuevos sujetos colectivos participantes) (Scherer-Warren, I. y Krischke, P.J., 1987; Vigevani, T., 1989). La producción normativa o de Derecho dejaría de corresponder a organismos técnico-formales separados de la población (instituciones y órganos representativos de monopolio estatal) para pasar a un nuevo e histórico "sujeto colectivo participante" conformado tanto por masas no organizadas como por organizaciones populares (sindicatos, etc.) o movimientos sociales (campesinos sin tierra, movimientos indígenas, originarios y campesinos, etc.)(4).

2. El segundo, mediante la construcción de un ejercicio de comprensión, interpretación y práctica jurídica pluralista que saque el Derecho del restringido ámbito de actuación de profesionales y operadores jurídicos (abogados y jueces, principalmente) y lo pase al conocimiento y práctica popular. Entonces serían los miembros de la comunidad en sus luchas por sus reivindicaciones los usuarios directos del Derecho, quienes adoptarían mecanismos para la defensa de sus propios intereses, quienes participarían directamente en la solución de sus necesidades y en la organización de la sociedad. (Muñoz Gómez, J.A., 1988: 59)

3. Y, el tercero, mediante, la aceptación como fuente generadora de derecho de nuevas prácticas sociales infra-estatales propias de los movimientos sociales (prácticas de economía popular o de democracia asamblearia basadas en la búsqueda de consenso de las que se deriva una dinámica fluctuante en la praxis de lo cotidiano asentadas sobre nuevos valores como la denominada "ética de la alteridad" (Dussel, E. ,1986; 1994; Dussel, E. y Apel, K.O., 1992.), etc.); lo que conllevaría la redefinición de la ordenación práctico-procedimental de las relaciones entre unos $y$ otros sobre la base de una nueva ética política de responsabilidad comunitaria.

(4) La oposición al modelo de monopolio del derecho estatal y la propuesta de reconocimiento de fuentes alternativas de producción normativa en el ámbito infra-estatal (grupos micro-sociales insurgentes) fue puesta de manifiesto ya, entre finales del siglo XIX y mediados del $X X$, por parte de las doctrinas pluralistas como las de Gierke, Haurior, Santi Romano, Del Vecchio, Ehrlich, Gurvitch, Griffiths, Thome, Rouland, Sally Falk Moore, Masaje Chiba y Vanderlinden, entre muchos otros. 
Reconfigurados estos tres niveles podríamos hablar, sin duda, de Derecho nuevo, entendido como mecanismo horizontal de autoorganización ciudadana, y no como mecanismo vertical de dominación. Sin embargo, es evidente que el paso del Derecho liberal al Derecho nuevo no se puede producir de manera instantánea e inmediata, sino que requiere de un proceso de transición.

\section{3. ¿El neoconstitucionalismo multicultural andino como Derecho Nuevo?}

El proceso constituyente colombiano de 1991 abrió un punto de inflexión en la evolución constitucional, no sólo latinoamericana sino mundial. En la Constitución colombiana aparecen, aún de forma imperfecta pero claramente reconocible, algunos rasgos novedosos y diferenciados con respecto al constitucionalismo clásico, que más tarde impregnarán los procesos constituyentes ecuatoriano de 1998 , venezolano de 1999, boliviano de 2006-2009 y, de nuevo, Ecuador en 2007-2008; y que, sin duda, nos permiten hablar de un nuevo constitucionalismo latinoamericano rupturista con el constitucionalismo clásico y que, cada vez más, va creando formas de Derecho nuevo. (Viciano, R. y Martínez, R., 2005)

Aunque quizá, de todos ellos, el proceso constituyente que más potencialidades ofrecía para avanzar más rápidamente en esta transición del Derecho liberal al Derecho nuevo, era el boliviano. Especialmente las propuestas surgidas de los debates constituyentes, y en menor grado, en el primer proyecto de Constitución aprobado por la Asamblea Constituyente de Bolivia, en Oruro, el 9 de diciembre de 2007 -que no el definitivo-, incorporaban todo un conjunto de novedades que ciertamente propiciaban el inicio de una reconfiguración, muy esperanzadora, de los tres niveles del discurso jurídico señalados, y que se plasmaba en un modelo multiorganizativo o multi-civilizatorio (comunitario) de Estado(5). Al final pero, la realidad ha sido otra.

\subsection{El modelo multi-civilizatorio o multi-organizativo (comunitario) de Estado como ilusión desvanecida}

La existencia, en Bolivia, de diversos sujetos colectivos conformadores de una unidad territorial que reivindicaban autogobierno (los departamentos del oriente del país y los pueblos y naciones indigenas), obligaba a tener que diseñar una ingeniería constitucional capaz de acomodar esta plurinacionalidad y pluralidad en una unidad política común. Y, para ello, como en cualquier país donde existe la necesidad de conseguir una acomodación legítima y estable, en el interior de un Estado plurinacional, de las naciones, pueblos y regiones existentes, se requería un 
diseño estatal que cumpliera dos condiciones de trayectorias opuestas (arriba-abajoy abajo-arriba) que, sólo en su integralidad, determinan la forma de Estado:

a) Arriba-abajo: la descentralización de competencias políticas, otorgando un mayor o menor grado de autogobierno político a estos entes territoriales (departamentales, regionales o indígenas) subestatales (autonomía).

b) Abajo-arriba: una representación territorial real y proporcional de los entes territoriales autónomos en la composición del sistema de instituciones y poderes de la estructura central del Estado.(6)

En el caso de Bolivia, si la nueva Constitución, que reconoce cuatro tipos de autonomía posibles: autonomía departamental (arts. 278-280), autonomía indígena originaria campesina (arts. 290-297) autonomía regional -indígena o no indígena(arts. 281-283) y autonomía municipal (arts. 284-285), hubiera concedido la posibilidad de que, al igual que los departamentos, las autonomías indígenas hubiesen podido configurarse libremente, sin ningún tipo de límites territoriales, como entidades tanto con plenas competencias para autogestionarse a mivel interno (arriba-abajo), como con proyección política externa hacia el Estado (abajo-arriba), hubiera supuesto, sin duda, el inicio de un proceso de reconfiguración de la organización territorial del país que hubiera llevado hacia un modelo multiorganizativo o multi-civilizatorio (comunitario) de Estado. Un modelo donde coexistirían diferentes entes autónomos territoriales plurales (departamentso, regiones indígenas y no indígenas, territorios indígenas originario campesinos), considerados no como meras creaciones de derecho o divisiones artificiales del territorio, sino como entidades históricas y culturales con entidad propia a las que se les reconoceria el derecho de regirse y organizarse por aquellos sistemas de relaciones sociales (formas jurídicas, económicas, sociales, culturales y de estructuración de gobierno y elección de autoridades) pre-capitalistas o capitalistas que les son propias (arriba-abajo). A la vez que, esta pluralidad de prácticas, tanto las tradicionales como las prácticas infra-estatales provenientes de los movimientos sociales o indígenas (asamblearismo, derecho comunitario, formas propias de elección de autoridades, economía popular, etc.), hubieran impregnado las instituciones centrales del Estado y su funcionamiento (abajo-arriba).

(6) Algunos autores han lla mado a estas dos condiciones de trayectoria opuesta (arriba-abajo / abajo-arriba) que definen la forma territorial de Estado, con el nombre de libertades colectivas negativas, esto es, la descentralización de competencias que garanticen, a los territorios subestatales, protección frente a las interferencias de las mayorías o de otras minorías, y libertades colectivas positivas, de participación en el gobierno compartido del Estado. (Ver: Requejo, F., 2007: 15). 
Sin lugar a dudas, ello hubiera supuesto un paso muy importante en la consolidación de un proyecto de emancipación y creación de un Estado y un Derecho nuevo. Como he explicado anteriormente, al ser, en la actualidad, el Estado liberal la única fuente de producción de discurso jurídico y de juridicidad, es también la única fuente de despliegue en la sociedad del sistema de representaciones que conforman "lo legitimo", lo cual blinda su reproducción (Noguera Fernández, 2009: 37). Ante este hecho, no cabe duda que cualquier proyecto de emancipación social o de construcción de una sociedad superadora del Estado-nación liberal, debe partir de la necesidad de desmonopolizar a éste de la función de producción jurídica, y este modelo multi-organizativo o multi-civilizatorio de Estado hubiera implicado la ampliación de los márgenes de lo "pensable" jurídicamente más allá de las fronteras de lo estatal-liberal, constituyendo, por tanto, una desmonopolización étnicooccidental del Derecho del Estado, esto es, una importante ruptura con el Estado y el Derecho de raíz liberal.

Sin embargo, los episodios de violencia impulsados por la oposición que amenazó con dirigir al país a una guerra civil, llevaron a la necesidad de conciliar el proyecto del Estado multi-civilizatorio del gobierno y los movimientos sociales, con la cruzada autonomista departamental de la oposición para el mantenimiento de sus privilegios de clase que, en un país con escaso desarrollo ind ustrial donde la estructura de poder económico y político se sustenta, todavía, en el control hegemónico de la tierra y el territorio(7), pasaba por mantener intacta la organización del territorio y la estructura de propiedad privada de la tierra(8). Todo ello, hizo que al final, la forma como quedara estructurada la organización territorial del Estado no fuera la descrita anteriormente, sino otra. En este sentido, dos de los grandes logros de la oposición en la negociación del texto final de la Constitución, sometido a referéndum popular el 25 de enero de 2009, fueron:

a) El mantenimiento de los límites territoriales departamentales intactos:

La Región (indígena o no indígena), como nueva entidad territorial creada por la nueva Constitución, hace referencia a un espacio conexo, relativamente o en

(7) Cerca del 90\% de la tierra cultivable del país se encuentra en régimen de haciendas medianas y grandes, mientras que el $10 \%$ restante recae en las comunidades campesinas y los pequeños productores. Familias como la familia Ante lo son propietarias en Santa Cruz de 116.647 hectáreas, o la familia Elsner de 115.646 hectáreas, o José Morales Sivant, de 101.598 hectáreas en Beri, para poner sólo algunos ejemplos (Datos del archivo del Instituto Nacional de Reforma Agraria (INRA))

(8) A pesar de que, en octubre de 1996, fue promulgada la Ley del Servicio Nacional de Reforma Agraria (5NRA), cuyos pilares fundamentales eran la clarificación de los derechos agrarios (saneamiento de tierras) y la titulación de tierras comunitarias de origen a favor de los pueblos indígenas, mandato del que se desprende el reconocimiento de tierras comunitarias de origen como propiedad colectiva, indivisible, inalienable, inembargable e imprescriptible, los resultados que se alcanzaron como consecuencia de la aplicación de la ley han sido mínimos, especialmente, después de la aprobación, en el periodo 2000-2002, de normas que relativizaban la noción de función económiça social (FE5) de la tierra, o normas de contrar reforma agraria. Todo ello ha permitido mantener todavía el citado régimen de concentración de gran parte de la tierra cultivable del pais en pocas manos privadas. 
términos culturales, socio-económicos y agroecológicos que, por una parte, se diferencia claramente de sus vecinos (región-en si), y por otra parte, cuenta con una población que se identifica con su región, esto es, que tiene un sentido de pertenencia (región-para 5i).(9)

La configuración de las regiones como nuevos entes territoriales de descentralización autónomos que pudieran, como estaba pensado inicialmente, incluso romper las fronteras departamentales, hubiera implicado una transformación de las estructuras de poder concentradas por las elites departamentales en la capital de cada departamento. Ello hubiera supuesto una re-configuración del espacio de poder departamental en sub-espacios orgánicos en los que se distribuye determinados volúmenes de poder, estableciéndose las reglas, los mecanismos y acciones legítimas por medio de los cuales las distintas comunidades (también rurales) pudieran autogestionarse, disputándole la estructura del campo de fuerzas a la elite departamental, tanto en su propio territorio regional, como en las instituciones centrales del Estado, mediante sus representantes territoriales.

No obstante, en el texto final fruto de las negociaciones entre gobierno $y$ oposición, estos últimos lograron incluir los actuales arts. 280.|(10), 280.|I|(11) y 301(12), no permitiendo a las nuevas regiones que se crearan traspasar límites departamentales ni asumir competencias sin el permiso del Consejo departamental, con lo que los departamentos, controlados por las elites departamentales urbanas, se mantenían tanto territorialmente, como en competencias, intactos. Además, lograron también otro elemento.

b) Elmantenimiento de los departamentos como territorio de referencia en la relación abajo-arriba:

En su versión final aprobada mediante referéndum, la Constitución boliviana establece en el Capítulo octavo (Distribución de competencias) del Título I de su tercera parte (Estructura y organización territorial del Estado), un régimen de

(9) Mauricio Lea Plaza Peláez define una "sociedad regional" como el espacio social donde se producen y reproducen un conjunto de prácticas y relaciones sociales particulares que permiten diferenciar una región de otra en un canjunto nacional. En este marco podemos entender que la moción de "sociedad regional" hace relación a una unidad estructural y política en espacios sociales propios, que interactúan permanentemente con otros y que se modifican de acuerdo a las fases de los procesos de desarrollo nacional. (Véase Plaza Pelaes, M. L., 2003: 245)

(10) Art. 280.I Constitución boliviana 2009: "La región, conformada por varios municipios o provincias con continuidad seográfica y sin trascender límites departamentales, que compartan cultura, lenguas, historia, economia y ecosistemás en cada departamento, se constituirá como un espacio de planificación ygestión".

(11) Art. 280.III Constitución boliviana 2009: "La región podrá constituirse en autonomía regional, a iniciativa de los mumicipios que la integran, vía referendo en sus jurisdicciones. Sus competencias deben ser conferidas por dos tercios de votos del total de los miembros del órgano deliberativo departamental".

(12) Art. 301 Constitución boliviana 2009: "La región, una vez constituida como autonomía regional, recibirá las competencias que le sean transferidas o delegadas". 
descentralización de competencias políticas en cada una de las unidades territoriales subestatales que reivindicaban autogobierno, creando entes territoriales autónomos departamentales, indígena originario campesinos, regionales y municipales, todos ellos, como instancias de autogobierno (art. 269 a 276). No obstante, el cumplimiento de esta primera condición (arriba-abajo), el grado de descentralización de competencias políticas, determina, como he explicado, sólo parcialmente la forma de Estado plurinacional. La forma de Estado plurinacional viene también, en su otra mitad, determinada por el mayor o menor grado de representación de los territorios autónomos en los órganos de la estructura central del Estado (abajo-arriba), lo que se materializa mediante la representación y participación de los entes territoriales autónomos subestatales en el gobierno central compartido yen sus instituciones.

Pues bien, el único ente territorial autónomo subestatal con representación en la estructura central del nuevo Estado boliviano son los departamentales, no los de reciente creación, los entes territoriales autónomos indígenas originarios campesinos, ni las regiones indígenas (evidentemente tampoco los municipios). Ello, sin embargo, no quiere decir que la población indígena no esté representada en la estructura central del Estado y por tanto, que la definición constitucional del Estado como plurinacional, establecida en el artículo 1 del texto(13), sea una mera declaración vacía. No!, los indígenas sí están, de acuerdo con la nueva Constitución, representados y participan de los órganos centrales del Estado, que por eso es plurinacional, pero su representación o articulación con éstos no se produce desde su propia territorialidad autónoma nacional (territorios autónomos indígenas), sino desde una territorialidad autónoma ajena, la departamental. Fijémonos en los dos siguientes ejemplos:

1 Uno de los elementos a través de los cuales se hace efectivo el carácter plurinacional del Estado es a través de la presencia de representantes de las naciones y pueblos indígenas en la Asamblea Plurinacional, compuesta por la cámara de diputados y la cámara de senadores (art. 145). Para el caso de la nueva cámara de diputados, los artículos 32 y 35 de la Ley electoral transitoria(14), señaló que los pueblos y naciones indigenas eligen, en las elecciones generales del pasado 6 de diciembre de 2009, a un representante por departamento. Es decir, los diversos pueblos y naciones indígenas ubicados en diversos territorios ancestrales dentro del departamento de Tarija (pueblos guaraní, Weenayek y Tapiete), por ejemplo, elegirán un

(13) Art. 1 Constitución boliviana de 2009: "Bolivia se constituye en un Estado Unitario Social de Derecho Plurinacional Comunitario (...)".

(14) La Ley Núm, 4021 del régimen electoral transitorio fue aprobada por el Congreso de Bolivia el pasado 14 de abril de 2009, y regula el procedimiento, desarrollo, vigilancia y control del proceso electoral para la constitución de la Asamblea Legișlativa Plurinacional, elección de la Presidenta o Presidente, vicepresidenta o vicepresidente v autoridades departamentales y municipales, en las elecciones del 6 de diciembre de 2009 y en las elecciones del 4 de abril de 2010 ; además de los referendos autonómicos, la elección de asambleístas departamentales y consejeros Departamentạles. 
representante común departamental que representará a los indígenas del departamento. Los mismo para el resto de pueblos y naciones indigenas ubicados en el interior de cada uno de los otros departamentos, exceptuando, los pertenecientes al departamentos de Chuquisaca y Potosí que no tendrán representante indígena en la cámara. Por tanto, habrá 7 representantes de los pueblos y naciones indígenas, uno por cada uno de los 7 departamentos con representación indígena, en la cámara alta. Con respecto a la cámara de senadores, la Constitución deja también claro que la representación territorial en la cámara se hará por departamentos, no por ningún otro de los entes territoriales autónomos: "I. La Cámara de Senadores estará conformada por un total de 36 miembros; II. En cada departamento se eligen 4 Senadores en circunscripción departamental, por votación universal, directa y secreta; III. La asignación de los escaños de Senadores en cada departamento se hará mediante el sistema proporcional, de acuerdo a la Ley" (art. 148).

2 Lo mismo sucede con otro de los elementos conformadores del carácter plurinacional del Estado, la composición mixta o plurinacional del nuevo Tribunal Constitucional, que está integrado por magistrados representantes de la justicia ordinaria e indígena. El art. 198 de la Constitución establece que los magistrados representantes de la justicia indígena postulados por los pueblos indígenas (art. 199.II), se elegirán (al igual que los magistrados representantes de la justicia ordinaria postulados por organizaciones de la sociedad civil) "por sufragio universal, según el procedimiento, mecanismo y formalidades de los miembros del Tribunal Supremo". A la vez, el art. 182.Il que establece el procedimiento para la elección de los miembros del Tribunal Supremo, dice: "La Asamblea Legislativa Plurinacional efectuará por dos tercios de sus miembros presentes la preselección de las y los postulantes por cada departamento y remitirá al órgano electoral la nómina de los precalificados para que éste proceda a la organización, única y exclusiva, del proceso electoral". Por tanto, el territorio de referencia para la postulación y elección de los magistrados indígenas vuelve a ser el departamento, no los territorios autónomos ancestrales indígenas.

En resumen, el único ente territorial autónomo que cumple las dos condiciones a partir de las cuales definir el modelo territorial de Estado: autogobierno (arriba-abajo) y representación en la estructura general del Estado (abajo-arriba), son los departamentos, y en consecuencia, estos se constituyen como el ente territorial autónomo de referencia para la construcción de la plurinacionalidad en su faceta abajo-arriba. El resto de autonomías territoriales quedan reducidas a corporaciones territoriales autorreferenciales con competencias para autogestionarse a nivel interno, pero sin proyección política externa hacia el Estado.

A diferencia de cualquier Estado autonómico o federal donde los entes autónomos subestatales articulan sus relaciones con la federación desde su territorio, 
en Bolivia, los indígenas tienen que articular sus relaciones con el Estado plurinacional, en su dimensión política, no desde su territo rio nacional, sino desde el territorio departamental ajeno. ¿Qué significa esto?. Pues que se fija un modelo de Estado plurinacional fundamentado en el reconocimiento de los derechos de los indígenas, entendidos como individualidades empíricas (que no es poco), pero no (al menos de forma completa) en los derechos de las naciones y pueblos indígenas, categoria que va indisolublemente unida a un territorio. (Noguera Fernández. A., 2010)

Lo que ha terminado haciendo la Constitución, en su versión final, es por tanto, no una redefinición del Estado y el Derecho, sino una evolución, ampliación y especificación de los derechos, incorporando como novedad el reconocimiento de derechos para los indígenas. Ello nos lleva a tener que hablar no de un Estado o un Derecho nuevo post-liberal, sino a un constitucionalismo liberal de tercera generación, el constitucionalismo multicultural. Y explico esto de manera más detallada.

\section{El constitucionalismo multicultural como constitucionalismo liberal de tercera generación}

No se puede analizar el poder sin tener en cuenta las contradicciones internad existentes en todo poder. Contradicciones que siempre han generado contrapoder. Las principales contradicciones del capitalismo a lo largo de su historia, han sido tres: la contradicción libertad-igualdad -o contradicción social-, la contradicción política y la contradicción cultural. Veamos cada una de ellas.

\subsection{La contradicción libertad-igualdad y la contradicción política}

La consolidación del capitalismo temprano en nuestras sociedades fue, desde sus inicios, unida a la aparición de dos fuertes contradicciones.

Por un lado, la universalización de la libertad (entendida como autonomía o individualidad) acentúa y agudiza su contradicción con la igualdad (equiparación real de los hombres en sus condiciones de vida), ya que, al darse primacía, por encima de todo, a la libertad del individuo (la equiparación real de todos los hombres para intervenir en el canje de productos), la igualdad sólo puede concebirse como instancia accesoria de la libertad, como "igual libertad", pero no como igualdad "real", puesto que la libre relación contractual de intercambio en la producción (compra-venta de fuerza de trabajo), descompone al pueblo en clases sociales desiguales económicamente.

Sólo una inversión de esta relación "libertad-igualdad", es decir, una primacía de la igualdad "común" como limitación de la libertad "individual" (liberación de la 
igualdad de su sujeción a la libertad), permite la des-enajenación del hombre mediante una comunidad de hombres "libres en cuanto iguales" (Cerroni, U., 1965: 170-173)

Asimismo, y por otro lado, durante el liberalismo temprano del siglo XIX, la ciudadanía política no era universal, sino patrimonial y patriarcal, sólo los varones en posesión de un cierto patrimonio podían votary ser elegidos.

Estas contradicciones internas del poder generaron contrapoder, la lucha del movimiento obrero, que puso al Estado liberal entre la espada y la pared, y que tuvo que ser apaciguado, siguiendo los consejos de Hegel, mediante la imposición de unos principios ficticios de reunificación de la sociedad (sittlichkeit) entorno al Estado liberal, que permitieron re-legitimar el mismo.(15) ¿Cuáles fueron estas ficciones?

\subsubsection{La ficción de la redistribución de la riqueza, expresada en el constitucionalismo social}

Algunas de las primeras Constituciones, en Europa, que incorporaron los derechos sociales fueron la Constitución española de 1931 o la de la República de Weimer de 1919 en la cual se establecían algunas normas tendentes a proteger determinados aspectos sociales. Después de la segunda guerra mundial, la tendencia de reconocer derechos sociales se reanudó con Constituciones como las de Islandia de 1944, Francia de 1946 y 1958, aunque esta última caracterizada por el acento autoritario que le imprimió De Gaulle, Italia de 1947, Alemania Occidental de 1949, Grecia de 1951 y 1975, Turquía de 1961, revisada en 1971 y en 1973-74, y de 1982, Portugal de 1976, revisada en 1982, 1989, 1992, 1997, 2001, 2004 y en 2005, y España de 1978. (Biscaretti Di Ruffia, P., 1996: 514)

(15) La concepción inorganicista, propia del liberalismo te mprano, que presentaba al Estado sólo como garante de un orden fundamentado en le mercado, fue a principios del siglo XIX criticada y modificada dentro de las filas del liberalismo, por Hegel. Hegel afirmaba que, la única manera de construir una estructura política estable, era mediante la creación de un consenso voluntario de los ciudadanos hacia esta, mediante la creación en los ciudadanos de valores éticos comunes que los cohesionaran en torno al Estado, ero lo que Hegel llamaba "Sittlichkeit", una eticidad común.

El planteamiento del liberalismo clásico, puramente individualista, decia Hegel, no consigue crear una "comunidad", no consigue articular una identificación del hombre con su sociedad capaz de legitimar o conseguir la identificación volunta ria de las sujetos con el Estado liberal y, en consecuencia, no permite articular una reproducción estable de la compleja sociedad moderna. Esta crítica al liberalismo clásico hizo que Hegel fuera acusado de ser un defensor de la Restauración y del Estado prusiano absolutista. En esencia, de ser un antiliberal. Esta interpretación comenzó en 1857, con un libro escrito por Robert Haym que dić inicio a la leyenda de Hegel como filósofo del Estado prusiano, y alcanzó un tratamiento antológico en la obra de K. Popper, La sociedad abierta y sus enemigos, quien lo colocó como iniciador de una tradición enemiga de la a abierta sociedad liberal (Popper, K., 1981). Más recientemente, autores como N. Bobbio o V. Pérez-Díaz han interpretado la concepsión hegeliana de la sociedad civil como expresión de una posición estatista y antiliberal (Bobbio, N., 1981; PerezDiaz, V., 1997). Sin embargo, a pesar de estas acusaciones, lo que hará Hegel no será mantener una posición opuesta al liberalismo, al contrario, está salvando la defensa de la libertad económica individual de las insuficiencias presentes en la ideología liberal previa aél, y, en consecuencía, está salvando el Estado liberal. 
No obstante, a pesar de incorporar en su articulado a un conjunto de derechos sociales, estas constituciones definen a los derechos civiles y políticos como derechos fundamentales, mientras que no otorgan tal fundamentalidad a los derechos sociales(16).

En este sentido, al definir los derechos individuales como fundamentales y los derechos sociales como no-fundamentales, estas constituciones están ubicando a los derechos individuales como derechos absolutos e inalienables que no pueden ser vulnerados por los poderes públicos ni los particulares, y a los derechos sociales como simples instrumentos funcionales para corregir las disfunciones de la antinomia libertad-igualdad, pero sin constituir, en ningún momento, un aspecto problemático para los primeros. Es importante diferenciar de aquellos modelos donde hay una "redistribución de la riqueza", de aquellos otros donde "se ayuda a la gente que lo necesita".

Alguien puede argumentar que ayudar a la gente que lo necesita es también un principio de redistribución pues hay recursos que son transferidos, es decir redistribuidos, desde aquellos que pagan impuestos hacia aquellos que reciben beneficios sociales. Sin embargo, este es un juego de palabras con trampa. La transferencia de recursos es sólo una consecuencia de la necesidad de financiar la ayuda a aquellos que la necesitan. En otras palabras, es evidente que hay un efecto redistributivo en el imperativo de ayudar a aquellos que lo necesitan, pero esto es una consecuencia residual de este imperativo, no su razón de ser. Y si no, fijémonos en el

(16) Existen varias tesis que han intentado justificar, sin demasiado éxito, este desigual trato a los diferentes grupos de derechos. Una de ellas es la que afirma que el desigual trato se debe a que los derechos civiles y políticos y los derechos sociales tienen distinta naturaleza jurídica. Concretamente afirma que los derechos sociales no son "auténticos" derechos sino otro tipo de normas legales, esto es, garantías institucionales, principios o directrices para guiar las políticas sociales (Hen kin, L., 1981; Robertson, A.H. y Merrills, J.G., 1989; Bossuyt, M., 1993). El principal argumento que se ha utilizado para afirmar esto, es que los derechos sociales no cumplen las características que cumplen todos los derechos, entre ellos los derechos civiles o políticos. La fórmula "X tiene un derecho a Y, en virtud de P", sólo es coherente, nos dicen, si se puede dar una explicación convincente: a) de quien es el titular del derecho $(x)$; $b$ ) de a qué tiene derecho, es decir, cual es el contenido del derecho $(Y) y, c)$ de la razón por la cual este sujeto tiene tal derecho. Estas explicaciones, nos dicen los defensores de esta tesis, sólo se pueden dar en el caso de los derechos civiles y políticos, pero no en el caso de los derechos sociales ya que no son derechos universales, no es posible establecer la naturaleza de las obligaciones que crean y no tienen su fundamento en valores morales sino en preferencias.

Otra de las teorizaciones que se han usado para justificar el desigual trato de los derechos civiles y políticos con respecto a los derechos saciales, es aquella que afirma que el desigual trato no se debe a la distinta naturaleza de los derechos sino a la distinta naturaleza de las medidas que se necesitan para hacer efectivos cada uno de estos grupos de derechos. Esta es una visión que parte de la diferencia establecida por C. Fried, en su obra "Right and wrong" (1978), entre los derechos civiles y políticos como derechos "negativos" y los derechos sociales como derechos "positivos". La clasificación responde al hecho de que, según afirman los defensores de esta visión (Kartashkin, V., 1982; Van De Luytgaarden, E., 1993), los derechos civiles y políticos no requieren de intervención del Estado para ser realizados y, por tanto, su cumplimiento es gratuito o casigratuito. En cambio, la aplicación de los derechos sociales sí requiere de intervención estatal así como de un importante gasto económico, lo que hace que sea mucho más dificil aplicarlos.

Sin embargo, ninguna de estas dos tesis, ni la de la distinta naturaleza de los grupos de derechos ni la de la distinta naturaleza de las medidas necesarias para implementarlos, son aceptables. Para ver, detalladamente, los argurnentos que desmienten estas dos tesis, puede consultarse Noguera Fernández. A. (2009a) 
siguiente ejemplo, puede ser que en una sociedad las medidas para ayudar a aquellos que lo necesiten sean efectivas y mejoren la calidad de vida de los pobres, pero al mismo tiempo la minoría rica de la población deviene cada vez más rica, en estas circunstancias las desigualdades sociales no son solventadas. (Espada, J.C., 1996: 128)

\subsubsection{La ficción de la oceptación de la voluntad política del pueblo como determinante de la acción de gobierno, expresada en la democracia representativa}

A la introducción, en el siglo XVIII, de la representación política(17), expresada en el parlamentarismo, le siguió como corolario principal, la tripartición de poderes(I8). La representación, como forma de ejercicio del poder, y tripartición de poderes, como forma de control del poder, se fusionaron perfectamente en el paradigma de la llamada democracia representantiva, que apareció para la burguesía liberal de la época como la salvación más importante ante el "extremismo" democrático y su poder negativo(19). Sin embargo, se puede poner en duda que, en la democracia representativa, los políticos representen realmente la voluntad e intereses de la ciudadanía. En primer lugar, porque los parlamentarios no son voceros de los electores ni de su voluntad, ya que no existe mandato jurídico en tanto no hay posibilidad de revocación de mandato(20). Por tanto, el representante no está vinculado a las órdenes del representado. $Y$, en segundo lugar, porque en la concepción de la representación liberal, el elegido no se constituye en representante

(17) La representación es una figura originaria del derecho privado, mediante la cual una persona Ilamada representonte asume la voluntad de otra incapaz, llamada representado, y actúa en nombre de ella, con gran libertad, de hecho el representante se subroga en la personalidad y en la voluntad del representodo, lo sustituye plenamente. En general requieren representante, los menores de edad y los incapacitados. Esta concepción concebía pues, al pueblo como una masa de analfabetos incapaces de gobernarse sin caer en la anarquia o el caos, con lo cual la única manera de garantizar la gobernabilidad, la protección y la libertad era mediante la delegación del poder soberano en manos de los más capaces supuestos representantes- (Ver: Bulté, J.F., 2004:97).

(18) Como corolario natural a la representación y mecanismo de control ante los posibles abusos de poder de los representantes, debía producirse, afirmaba Montesquieu, la tripartición del poder en tres poderes, con capacidad cada uno de e los de limitar el poder del otro. La tripartición de poderes es en consecuencia un sistema de autocontrol del poder (separado del pueblo) mediante unos mecanismos de "pesos y contrapesos" entre los poderes del Estado.

(19) Es notable ver como Montesquieu, en el famoso libro XI de El Espiritu de las Leyes, no asume la representación y la distribución de los tres poderes del Estado, como una expresión solamente propia de un sistema idóneo, sino coma una alternativa liberadora frente al modelo antiguo greco-latino (basado en el Tribunado y su poder negativo). La representación política y la tripartición de poderes, se desenvuelven, a partir de este momento, como instituciones defensivas del abuso de poder y sobre todo de las salidas contrarias fácilmente reconocibles en el sistema jurídico y constitucional romano-latino: el conjunto de poderes negativos sintetizados en el Tribunado (Fernández, J. A., 2005: 46).

(20) En el mandato, figura también originaria del derecho privado, se produce un contrato consensual, por el que una persona llamada mandante, que dispone de total lucidez y capacidad, ordena a otra llamada mandatario que haga en su nombre tal o cual gestión. No obstante, el mandante no enajena su personalidad ni voluntad, sino que simplemente cede algo de autoridad para que, en su nombre, el mandatario haga determinadas diligencias y vigila constantemente el cumplimiento del mandato, reservándose el derecho de rescindir el mandato en cualquier momento. 
del cuerpo electoral que lo eligió sino en representante de ese ente abstracto que es la "nación", pudiendo este hablar en nombre de toda una "nación" que no lo eligió.(21)

\subsection{La contradicción cultural}

Conjuntamente con las dos contradicciones anteriores, otra de las contradicciones propias del liberalismo es la contradicción cultural. Contradicción que ha explotado durante los últimos años en América Latina, fruto de la lucha del movimiento indígena-popular, y con la que se está operando de la misma manera con que se resolvieron las dos contradicciones anteriores que explotaron a finales del siglo $\mathrm{XIX}$ inicios del XX. Esto es, ante la explosión de una contradicción que amenaza el sistema, el Estado adopta un conjunto de principios ficticios de reunificación de la sociedad entorno al Estado para re-legitimarse. Aquí la ficción adoptada es la ficción de la igualdad cultural, expresada en el nuevo constitucionalismo multicultural.

Pero empecemos por ver como se ha expresado la contradicción cultural en Latinoamérica.

Partiendo de aquellas concepciones que perciben el poder como producción cultural (Gramsci, Foucault, Bourdieu, etc.), y buscando cuales son los mecanismos de elaboración-difusión de la cultura, entendida no como folklore sino como un sistema de relaciones sociales autorreproductor, encontramos, como ya expresé anteriormente, el Derecho. Pero, ¿cómo el Derecho elabora-difunde cultura y, por tanto, hegemonía? A través de la creación de sujetos. Esto nos lleva a la noción de identidad jurídica.

La identidad jurídica es tratada generalmente en su acepción puramente normativa en el marco del derecho positivo, correspondiendo su desarrollo a dos campos normativos: en primer lugar, el que corresponde al derecho constitucional y

(21) Ya en 1925, Karl Schmitt hizó una critica severa al parlamentarismo de principios de $/$ sig|o XX. Decia Schmitt: "Comisiones reducidas (...) de los partidos (...) deciden a puertas cerradas, y lo que acuerdan en pequeño comité los representantes de las intereses gran capitalistas es para (...) millones de hombres, de mayor importancia que todas las decisiones políticas. El moderno parlamentarismo, la exigencia de control y la creencia en la publicidad, (...) icuán inofensivos e idílicos nos parecen hoy los objetos de aquella política de gabinete de los siglos XVII y XVIII en comparación con los destinos (...) que hoy (...) son objeto de toda suerte de misterios, segu ramente hoy habrá muy pocos hombres que quieran renunciar a las viejas libertades liberales, a la libertad de palabra y de prensa (...) y todavia habrá menos que crean que la legislación y la política justas y verdaderas nacen de los artículos periodísticos, de los discursos de mitin y de los debates parlamentarios. Si la publicidad y la discusión se han convertido en la realidad efectiva de la práctica parlamentaria, en una formalidad vacua y nula, tenemos la prueba de que también el parlamento, tal como se ha desenvuel to hasta ahora como institución, ha perdido su sentido y sus supuestos scciológicos y espirituales" (Schmitt, K. Sobre el parlamentarismo. Cit. por Kelsen, H., 1934:526) 
que obra o se manifiesta como un derecho político inherente al ser humano. Este derecho político es el que corresponde a la identidad propiamente dicha y que permite contar con una nacionalidad y con un nombre, acto jurídico que deriva del nacimiento de una persona en un territorio (Estado) y tiempo determinado (lus Soli), o por el reconocimiento al derecho de sangre (Jus sanguinis). Así, la identidad corresponde a aquellas personas a quienes se les reconocen determinados derechos y obligaciones en virtud de haber nacido en el marco del Estado nacional.

El segundo campo normativo del problema en cuestión se expresa fundamentalmente a partir del derecho civil. Encontramos que de dicha identidad jurídica anterior (nacionalidad) se desprende su realización como persona mediante la ejecución de diversos actos jurídicos o de la participación en diversas relaciones sociales. (Durand, Ch., et. al., 2003)

Diferenciamos pues dos elementos distintos de la identidad aunque ligados en su pretensión: por una parte el del derecho originario, que corresponde a la identidad jurídica, es decir, el derecho a la nacionalidad y a un nombre; por la otra, la certeza jurídica, que consiste en la realización de la persona y en la ejecución de diversos actos jurídicos. De acuerdo con esto, podemos afirmar que la identidad jurídica se compone de dos (sub)identidades:

a) La identidad constitutiva (la noción de "sujeto de derecho"):

La noción de sujeto es la ficción fundante de todo sistema jurídico. La estructura del derecho moderno se organiza y se sostiene en torno a la categoría de sujeto, el Derecho siempre interpela a un "hombre". Ahora bien, es mediante el discurso jurídico que se explica cómo el Derecho interpela al sujeto que este hombre se constituye (identidad). Es mediante la institución juridica que los hombres toman conciencia de sí y se ven siendo como lo que el Derecho les dice que son (Ruiz, A., 1991). La Constitución y el Código Civil establecen quiénes son personas (esto es sujetos de derecho), tipo y extensión de su capacidad, cualidades y atributos tales como el nombre, el domicilio, los requisitos que deben cumplir para la realización de hechos y actos juridicos, etc.. Es a partir de mirarse y reconocerse en ese modelo que aparece la imagen de cada uno en el espejo (la imagen que cada hombre tenga de su propia existencia depende del modelo de hombre implicado en el discurso jurídico). Sin identificación no hay identidad.

En consecuencia, los hombres no inventan el Derecho después de estar constituidos como sujetos sino que es el Derecho el que inventa el sujeto (en el discurso liberal sujeto como "ente susceptible de adquirir derechos y contraer obligaciones"), lo que significa que es desde el poder que se constituye el "sujeto de derecho", que se dota de identidad a todo aquel al que instituye como tal. 
b) La identidad interpelativa (la noción de "sujeto con derechos"):

Una vez el derecho constituye el "sujeto", lo interpela. La Ley lo alude, le habla, lo autoriza, lo interdicta, le prohíbe, le establece algún lugar en el campo de la legitimidad o lo excluye de él, le otorga la palabra o le priva de ella, etc.. Cada una de estas interpelaciones está orientada hacia ciertos individuos que, supuestamente, ya están constituidos como sujetos de derecho. (Ruiz, A., 1991)

Mediante las interpelaciones del discurso jurídico (se nombra a los individuos como sujetos específicos y no como sujetos en general: "acreedor", "deudor", "homicida", "pródigo", "buen padre de familia", etc.), el Derecho establece las inter-relaciones entre los sujetos de derecho que permiten a éstos, constituir un sistema de relaciones sociales auto-reproductivo, dentro del cual se sienten provenientes y reproductores de sí mismos, herederos, transmisores y actores de una determinada manera de estructurar su espacio (identidad).

A pesar de esta separación metodológica, la identidad jurídica es una, no pueden en la práctica separarse o marcar una frontera entre la (sub)identidad constitutiva y la interpelativa en cada sujeto. Existe una "simultaneidad" en el hecho de constituirse como sujeto de derecho y establecer inter-relaciones jurídicas. Adquirir la condición de sujeto supone reconocimiento de la existencia de un cierto tipo de relaciones con otros $y$, al mismo tiempo, ocupar un lugar determinado para el cruce de relaciones me constituye como sujeto al interpelarme.

Evidentemente, no cabe duda que toda noción de sujeto constituidointerpelado (en el discurso jurídico liberal-individualista, el sujeto de derecho "libre" $y$ "autónomo") constituye una ficción fundante a partir de la cual se ordena una sociedad históricamente determinada y la vida de los individuos que viven en ella, en tanto se vuelve una clave interpretativa fundamental de la organización social, política y económica (a cada manera de conceptualizar, mediante el Derecho, al "sujeto" y su naturaleza corresponden formas definidas de mentar los actos acordes a las necesidades del poder que lo instituye como tal). Toda construcción histórica de una noción contitutivo-interpelativa de sujeto va acompañada pues, de la creación de un imaginario simbólico-racional tendiente a justificar y legitimar las instituciones $y$ estructura social de la formación socio-histórica en cuestión, su funcionamiento, su origen, su organización y sus objetivos. En consecuencia, denominaré "identidad jurídica"

al conjunto de normas juridicos, órganos y formos de orgonizoción del poder, derechos y obligaciones, mecanismos de resolución de conflictos declarados en la sociedad, etc. que, resultado de la creación mediante el Derecho de una determinada noción de sujeto constituido-interpelado, constituyen un 
determinado vivir "asumido" colectivamente de manera diferenciada por un grupo social concreto. (Noguera Fernández, A., 2009: 33)

Será a partir de la creación de esta identidad jurídica como espacio de reproducción dialéctica entre la esfera del "ser" (pensamiento) y la esfera del "hacer" (acción) que un sistema socio-económico en cuestión se convierte en una realidad "naturalizante" (concebida como "natural" y "necesaria") y por tanto, en hegemónica políticamente.

En el Estado-nación occidental, la construcción de la identidad jurídica se ha hecho alrededor del modelo jurídico dominante, el positivismo jurídico de raíz liberaly su propia noción de sujeto. En el mundo occidental, donde los países son plurinacionales pero uni-societales (regidas por un único sistema de relaciones políticas, jurídicas, sociales, económicas), ello ha llevado a un "blindaje" de la forma Estado-nación moderna. Sin embargo, en América Latina, donde los países son comunidades multi-societales (conviven, en su interior, distintos sistemas de relaciones políticas, jurídicas, sociales, económicas), este modelo, al intentar estructurar el conjunto de representaciones que conforman lo legítimo alrededor de una única identidad cultural, la liberal-occidental, ha dado lugar a la exclusión del sistema de una gran parte de la población que se autoidentifica como indígena y que, en algunos países andinos, son más de la mitad de la población(22). El afloramiento de la contradicción cultural ha generado, a la vez, el surgimiento de contrapoder encabezado por el movimiento indígena-popular, que ha tenido que ser apaciguado por una nueva ficción de reunificación de la sociedad entorno al Estado liberal, la ficción de la igualdad cultural expresada en el nuevo constitucionalismo multicultural.

\subsubsection{La ficción de la igualdad cultural, expresada en el constitucionalismo multicultural}

En los países latinoamericanos el reconocimiento de la multiculturalidad no se ha hecho, como ya he expresado anteriormente, sobre la base de un modelo de pluralidad (política, jurídica, económica, social) integral, centrado en la idea de que el Estado está integralmente constituido por una pluralidad de prácticas que se "interpenetran", "influyen"y "limitan"(23), tanto en la vida cotidiana de los ciudadanos como

(22) A modo de ejemplo, en el año 2001, la población indígena constituía entre el 55 y el 70\% de la población en Bolivia. En Perú, en el año 2000, eran el $47 \%$ de la población. En Ecuador, también en el 2000, constituían el $37 \%$ de la población. (Gregor Barié, C., 2003: 45).

(23) Este modelo de pluralismo jurídico no implica tampoco que bajo el derecho de identidad cultural se permita todo y no se establezca ningunos mínimos o límites fundamentales a respetar. El Derecho Humano a la identidad cultural debe valorizar lo particular pero no debe negar la universalidad de determinados Derechos Humanos, pero se trata de límites establecidos no desde la imposición de la hegemonía o universal validez de un derecho occidental, sino a partir de la inter-penatración e influencia recíproca de los diversos órdenes normativos. 
en la propia estructura central del Estado. La multiculturalidad se ha construido sobre la lógica de que ante el problema de un sector de la población que no participa de la cultura hegemónica liberal, se les reconocen un conjunto de derechos a la diferencia como mecanismo de integración. Ante una situación de desigualdad estructural, la igualdad se consigue a través de la diferencia, pero sin que ello suponga modificar sustancialmente la lógica liberal de funcionamiento general del Estado y la sociedad. Se trata del llamado principio de "inclusión del controrio", el cual explica el destino de la jerarquía en esta ideología moderna basada en la idea de igualdad. Tal y como manifiesta L. Dumond (1991: 140-141), la jerarquía no ha desaparecido de las sociedades modernas, sino que ha sido absorbida por el mito de la igualdad: lo que nosotros valoramos está implícitamente construido como punto de referencia para una categoría general que eng loba diferentes valores. Por ejemplo, en el encuentro de culturas consideramos al otro como igual a nosotros, incluyéndolo en la categoría común de género humano; pero al mismo tiempo, la referencia implícita desde la que se construye nuestra imagen del "género humano" es nuestro propio punto de vista. Así los diferentes valores y modos de organización están explícitamente construidos como iguales a los nuestros. Si nosotros tenemos derecho, otras sociedades deben tenerlo también. Sin embargo, como nuestros propios valores y concepciones son el punto de referencia, las concepciones y valores ajenos son considerados, de hecho, como jerárquicamente inferiores. Su originalidad queda descalificada $y$, con frecuencia, la imagen de los otros, de sus valores, de sus concepciones e instituciones, consiste en la imagen invertida y degradada de nosotros mismos y nuestros valores. (Eberhard, C., 2003: 266-267)

Así, artículos como el art. 246 de la Constitución colombiana de 1991, que establece que se podrá ejercer la jurisdicción indígena en los territorios indígenas, pero "siempre y cuando se respete la Constitución y la Ley", son ejemplo de un reconocimiento de los derechos indígenas desde el modelo de la "inclusión del contrario", esto es un modelo de reconocimiento de la jurisdicción indígena, de sus procedimientos de resolución de conflictos y sistema punitivo, pero bajo un régimen de control o supervigilancia de la jurisdicción ordinaria estatal sobre ésta, para asegurarse que respete los derechos humanos. Se trataría de un régimen de control, revisión y, por tanto, de subordinación, lo que entraría a la vez en contradicción con el a la identidad cultural de estos pueblos(24).

(24) El artículo 246 de la Constitución colombiana causó la famosa sentencia T-349 de la Corte Constitucional de Colombia, mediante la cual manifestó que no todas las normas constitucionales y legales pueden constituir un límite a las funciones jurisdiccionales de las autoridades incígenas, de lo contrario "el reconocimiento de la diversidad cultural no tendría más que un significado retórico". El juez constitucional a través del principio de la "maximización de las comunidades indígenas" $y$, por tanto, de la "minimización de las restricciones" a las indispensables para salvaguardar intereses de mayor jerarquía, determinó que las autoridades indígenas que ejercen funciones jurisdiccionales se encuentran sometidas a unos "mínimos aceptables", por lo que "sólo pueden estar referidos a lo que verdaderamente resulta intolerable por atentar contra los bienes más preciados del hombre". En efecto, la corporación señaló que este "núcleo de derechos inta ngibles incluirá solamente el derecha a la vida, la prahibición de la esclavitud y la prahibición de la 


\section{Los aportes del constitucionalismo liberal de tercera generación}

En consecuencia, y respondiendo a la pregunta que formulaba en la introducción de este trabajo, el nuevo constitucionalismo latinoamericano, a pesar de las esperanzas que generó inicialmente en los sectores progresistas, no ha acabado conformándose como un modelo creador de un Estado y un Derecho nuevo superador del modelo liberal, sino más bien, como una evolución, ampliación y especificación de los derechos liberales.

No obstante, ello no puede concebirse tampoco como un fracaso. El nuevo constitucionalismo (del malestar) latinoamericano, es un constitucionalismo que recobra la función de garante de los derechos de los excluidos frente a las posibles arbitrariedades de los gobernantes y poderes privados, y ello debe valorarse como muy positivo. Se trata de un nuevo constitucionalismo que está creando una forma constitucional propia, reconocible en varios de sus productos, que va tomando perfiles claros y que, en muchas ocasiones, cuenta con notables diferencias en lo que se ha entendido como "correcto" en la doctrina constitucional clásica europea o norteamericana. Seguramente, uno de los elementos más vanguardistas y destacables de estas constituciones es, entre otros, el tratamiento que hacen de los derechos y de sus garantías. Se trata de textos que abren grandes oportunidades para poder hablar de la conformación de una nueva cultura jurídica en materia de derechos, esto es, de un nuevo constitucionalismo de los derechos.

\subsection{El tratamiento constitucional de los derechos: reconocimiento, igual jerarquía, indivisibilidad y justiciabilidad}

Hablar de las últimas constituciones aprobadas en los países andinos durante los últimos años, es hablar de textos constitucionales caracterizados por conformar una nueva cultura jurídica, sin precedentes en el constitucionalismo comparado, en materia de reconocimiento, protección y justiciabilidad de derechos. Los aspectos presentes en estas constituciones que nos permiten hablar de un nuevo constitucionalismo de los derechos son, básicamente tres: un extenso listado y un desarrollo casi reglamentario de los derechos; un tratamiento constitucional de los derechos basados en los principios de igual jerarquía e indivisibilidad; y, el establecimiento de un amplio sistema de garantías constitucionales para la protección de los derechos.

tortura". Además, la Corte adicionó a este conjunto de derechos, el derecho del sujeto a un "debido" proceso (previsibilidad) adeçuado a su cultura, esto es a ser juzgado según las normas y procedimientos pre-existentes en su cultura. (Calambia. Carte Constituciana I. Sentencia T-349 de 1996. M. P. Carlas Gaviria Díaz). 
La combinación de estos tres elementos permite garantizar, como nunca antes, el acceso a los derechos de los grupos sociales vulnerables, tradicionalmente excluidos.

En cuanto al primero de estos tres elementos, el extenso listado y desarrollo de los derechos, las nuevas constituciones andinas no sólo incorporan a los derechos ya reconocidos previamente, y una gran cantidad de derechos que no aparecian en constituciones anteriores, como pueden ser el derecho a la vivienda, derechos laborales de los trabajadores informales, derechos de las mujeres, derechos de los pueblos y naciones indígenas, etc., sino que además, otorgan a todos estos derechos, viejos y nuevos, un mayor desarrollo del contenido de cada uno de ellos, así como de sus indicadores y del papel del Estado para el logro de su satisfacción. La ampliación del articulado de derechos en las constituciones latinoamericanas de las dos últimas décadas "no es en sí mismo bueno o malo, pero puede considerarse que, en el caso de la explicitación de los derechos particulares de los grupos vulnerables, se ha generado un avance representado por las mayores oportunidades para que esos derechos sean objeto de atención pública, de procesos de planificación estatal o de formulaçión de políticas y leyes" (Aponte, C., 2000: 119). Esta extensión, casi reglamentaria, de los derechos, que se da especialmente en las constituciones de Colombia (1991), Ecuador (1998), Venezuela (1999), Ecuador (2008) y Bolivia (2009), si bien no sería aceptable desde la puridad de la técnica constitucional ortodoxa, es algo que responde a las condiciones, necesidades y objetivos de las nuevas constituciones y sus respectivas sociedades. Necesidades que tienen que ver: a) que los distintos poderes se vean obligados a darle más eficacia a derechos que se concretan; b) con la generación de un modelo integral que aúne de forma completa las distintas generaciones para conectar una función técnico-constitucional con la realidad social; $\gamma, c)$ con una función didáctica e integradora en unas sociedades con altas tasas de analfabetismo y un muy alto analfabetismo funcional en cultura cívica (PALACIOS, F., 2006: 105)

En cuanto al segundo elemento, la igual jerarquía e indivisibilidad de los derechos, todas estas constituciones suponen una plena reactivación de los derechos sociales y económicos como derechos "de primera", plenamente protegidos y justiciables, y al mismo nivel y jerarquía que los civiles y políticos.

Si nos fijamos, en las Constituciones de Venezuela de 1999 y de Ecuador de 1998 y 2008, ya no se habla de "derechos fundamentales", sino simplemente de "derechos" ode "derechos humanos".

Normalmente se habla en los textos constitucionales de "Derechos Fundamentales" para establecer algún tipo de diferencia entre todos los derechos que aparecen en la Constitución. Esta diferencia expresa que en la Constitución no sólo aparecen los derechos explícitos en la declaración de derechos, los fundamentales que son de aplicación directa, sino que a lo largo del texto constitucional aparecerán 
muchos otros derechos de desarrollo legislativo. Además, la consagración positiva de un derecho como Fundamental obliga a los operadores juridicos a maximizar, en el momento de la interpretación constitucional, los mecanismos que permitan su protección frente a otros. Sin embargo, en modelos donde las diferencias entre derechos ya no existen en el orden lógico-deóntico, ni en la ausencia o presencia de características como la exigibilidad judicial, o en cuanto a las obligaciones que generan, lo que sucede en el caso de las Constituciones de Venezuela y Ecuador, ¿qué sentido tiene continuar manteniendo la diferenciación entre derechos fundamentales y no fundamentales?. Esta es una diferenciación que sólo es útil a paradigmas ideológico-políticos de negación parcial de derechos, pero no a modelos basados en la indivisibilidad e interdependencia de los derechos. Es por eso que ni la Constitución de Venezuela de 1999 ni las Constituciones de Ecuador de 1998 y 2008 ya no usan la expresión "derechos fundamentales", sino que, como decía antes, hablan sólo de "derechos" o "derechos humanos". En el caso de la Constitución boliviana, si bien si usa todavía la expresión de "derechos fundamentales", la igual jerarquía e indivisibilidad de los derechos queda clara a través del artículo 13 de la misma, donde se establece que:

los derechos reconocidos por la Constitución son inviolables, universales, interdependientes, indivisibles y progresivos", asi como que "los derechos que proclama esta Constitución no serán entendidos como negación de otros derechos no enunciados" y que "la clasificación de los derechos establecida en la Constitución no determina jerorquía alguna ni superioridad de unos derechos sobre otros.

$\mathrm{Y}$, finalmente, en cuanto al tercer elemento, son varias las garantías que estas Constituciones establecen para garantizar la justiciabilidad de los derechos. En primer Iugar, las Constituciones a que nos referimos fijan un conjunto de recursos jurisdiccionales, es decir, recursos concretos que permiten a los particulares titulares de derechos oponerse a la arbitrariedad o la pasividad de las autoridades, o de otros particulares, y promover el reconocimiento y la efectividad de sus derechos. Estos son entre otros: el tradicional recurso de amparo; el recurso de inconstitucionalidad para solicitar la nulidad normas legales promulgadas y que sean contrarias a los derechos constitucionalmente establecidos; la acción de cumplimiento para evitar situaciones de omisión que impliquen vulneración de derechos constitucionalmente reconocidos como por ejemplo la tardanza en la producción de leyes de desarrollo constitucional necesarias muchas veces para tornar efectivas determinadas cláusulas "programáticas" de la Constitución, o la mora en la ejecución, es decir, supuestos donde hay decisiones tomadas pero que no se cumplen, como podría ser el caso de una jubilación o un retiro ya otorgado, pero que no se paga; las llamadas acciones colectivas, entre ellas la acción popular, que permiten superar los límites procesales e inadecuación de los mecanismos procesales tradicionales para proteger determinados derechos sociales o colectivos. Los mecanismos tradicionales de 
justiciabilidad de los derechos fueron creados dentro del paradigma de los derechos de propiedad del siglo XIX, esto determina de manera clara su naturaleza (López, J. R., 1994: 114-138). Se trata de formas procesales que fueron desarrolladas pensando en juicios bilaterales o conflictos entre individuos privados. Ello provoca, por ejemplo, que sean mecanismos que no sirvan para tramitar demandas colectivas de protección de derechos de grupos de personas que comparten una situación similar y que son situaciones que requieren de un remedio colectivo. O que se trate de mecanismos procesales que exigen una gran cantidad de pruebas cuando las violaciones de derechos sociales, a menudo, requieren de urgente resolución; etc.

Pero conjuntamente, con los diferentes recursos jurisdiccionales previstos, las Constituçiones señaladas establecen también otras características. Una de ellas es la de la aplicabilidad directa de todos los derechos, también los sociales y colectivos, esto es, que por el simple hecho de estar reconocidos en la Constitución son derechos directamente exigibles por vía judicial por parte de los interesados en casos concretos, independientemente de si existe o no legislación que los desarrolle. La vinculación, por tanto, de las autoridades del Estado y de los particulares a estos derechos es absoluta. El objetivo del principio de aplicabilidad directa es evitar el fenómeno de la "legislación negativa", es decir, que por falta de leyes que desarrollen estos derechos no puedan tener eficacia. En las Constituciones de Venezuela de 1999, de Ecuador de 1998 y 2008, así como en la Constitución boliviana de 2009, optar por igual jerarquía de los derechos sociales $y$ económicos y los derechos civiles y políticos, implica obviamente optar por la aplicabilidad directa de los primeros(25).

Además de establecer la aplicabilidad inmediata de todos los derechos establecidos en la Constitución, los cinco textos reconocen explícitamente, al igual que la Constitución argentina incorporó en su reforma del año 1994, la aplicabilidad directa de los derechos establecidos en tratados internacionales de derechos humanos, lo que incluye, entre otros, el Pacto Internacional de Derechos Económicos, Sociales y Culturals (PIDESC) o el Protocolo Adicional a la Convención Americana de Derechos Humanos en materia de Derechos Económicos, Sociales y Culturales, conocido también como Pacto de San Salvador(26).

(25) El artículo 18 de la Constitución ecuatoriana de 1998 y el art. 11.3 de la Constitución de 2008, establecen la aplicabilidad directa de los derechos reconocidos por la Constitución. Asimismo, el artículo 22 de la Constitución venezolana afirma : "... La falta de ley reglamentaria de estos derechos no menoscaba el ejercicio de los mismos". El articulo 110 de la Constitución boliviana dice: "todos los derechos reconocidos en la Constitución son directamente aplicables".

(26) El artículo 18 de la Constitución ecuatoriana de 1998 y el 11.3 de la de 2008 establecen: "Los derechos y garantías establecidos (...) en los instrumentos internacionales de derechos humanos serán directamente e inmediatamente a plicables pory ante cualquier juez, tribunal, autoridad o funcionario, de oficio oa instancia de parte".

El artículo 23 de la Constitución venezolana dice: "Los tratados, pactos y convenciones relativos a derechos humanos, suscritos y ratificados por venezuela, tienen jerarquía constitucional y prevalecen en el orden interno, en la medida en que contengan normas sobre su goce y ejercicio más favorables a las establecidas por esta Constitución y la ley de la República, y son de aplicación inmediata y directa por los tribunales y demás órganos del Poder Público." Ya en el artículo 128 de la 
El reconocimiento de jerarquía constitucional a los tratados internacionales de derechos humanos, refuerza la operatividad de los derechos, por varias razones: la primera, debe tenerse en cuenta la responsabilidad internacional que el Estado asume con la adopción de tales documentos ante un eventual incumplimiento de las normas allí establecidas (Fayt, C. S., 2007: 89). Y, segundo, la sola adhesión a estos instrumentos comporta la asunción por el Estado de tres obligaciones principales: respetar los derechos protegidos, garantizar el goce y pleno ejercicio de aquellos derechos a las personas que se encuentran bajo su jurisdicción, $y$ adoptar las medidas necesarias para hacer efectivos tales derechos (Pinto, M., 2004: 47)

En resumen, queda claro como las Constituciones de Ecuator del 98, la venezolana del 99 y las de ecuador de 2008 y Bolivia de 2009 establecen sin rodeos, la posibilidad de exigilidad inmediata ante los tribunales locales de todos los derechos, tanto los contemplados en la propia Constitución como en los tratados internacionales de derechos humanos.

Otra garantía que las citadas Constituciones fijan es el principio de prohibición de regresividad de los derechos. Tanto la Constitución venezolana de 1999, la Constitución ecuatoriana de 2008 y la boliviana de 2009, reconocen en sus artículos 19, 11.8 y 13.1 respectivamente, el principio de progresividad de los derechos, del cual se deriva la prohibición de regresividad de los mismos. Asimismo, de manera explícita, la nueva Constitución ecuatoriana de 2008 en su artículo 11.4 señala: "Ninguna norma juridica podrá restringir el contenida de los derechos ni de las garantias constitucionales".

Finalmente, se reconoce también la figura de la reserva de ley orgánica en materia de derechos. Normalmente suele calificarse a la reserva de ley orgánica como un mecanismo de protección de los derechos. Se trata de una garantía que reside en la fuente que la produce, el Parlamento, y que establece que cualquier regulación que desarrolle los derechos fundamentales requiere para su aprobación mayoría cualificada de los votos de la cámara. Su objetivo se basa en el hecho, que los derechos

anterior Constitución venezolana de 1961 establecía un mecanismo mediante el cual los tratados sé incorporaban al orden interno de manera positiva, yen materia de tratados internacionales de derechos humanos este artículo se reforzaba con el 50, lo que otorgaba rango constitucional a los derechos recogidos en tratados internacionales de derechos humanos por considerarlos inherentes a la persona. La Constitución de 1999, por su parte, en el citado artículo 23 desarro la y actualiza esta tendencia incluyendo lo que se conoce en la doctrina como la "cláusula del individuo más favorecido", que implica se ap licará al ciudada no la normativa que amplié en mayor medida sus derechos y garantías (Pérez, M., 2004: 187-188). Y, el artículo 256. I de la Constitución boliviana señala también: "Los tratados e instrumentos internacionales en materia de derechos humanos que hayan sido firmados, ratificados o a los que se hubiera adherido el Estado, que declaren derechos más favorables a los contenidos en la Constitución, se aplicarán de manera preferente sobre ésta". Aunque no aparecía en la Constitución anterior ningún artículo de esta naturaleza, el Tribunal Constitucional boliviano incorporó en el 2003 y el 2004, mediante su jurisprudencia (Sentencias 1662/2003-R y 1494/2004-R), los tratados internacionales de derechos humanos en el llamado "bloque de constitucionalidad". (Dermizaky, P., 2006: 131-132). 
fundamentales son posiciones tan importantes que su otorgamiento o nootorgamiento no puede quedar en manos de mayorías parlamentarias coyunturales (Alexy, 1997: 432). Ello de por sí define que no pueden ser materia de reforma sustancial por vía legislativa ordinaria o administrativa, la plena e incontrolada disposición de los derechos por parte del poder político acabaría por transformarlos en simples instrumentos de la voluntad política, lo que es absolutamente incompatible con la noción de dignidad humana. La reserva de Ley orgánica está por tanto vinculada con la noción de seguridad jurídica la cual, a la vez, guarda íntima relación con la prohibición de regresividad de los derechos.

La Constitución de Venezuela de 1999 dispone en su artículo 203 que el desarrollo de los derechos constitucionales, sin establecer distinción alguna, corresponde a ley orgánica. No queda muy claro en el precepto la mayoría exigida para aprobar las leyes orgánicas, pero parece que han de ser los dos terceras partes de los integrantes de la Asamblea Nacional, pues así se requiere para su reforma.

La Constitución de Ecuador de 1998, el artículo 142.3 establece reserva de ley orgánica para la regulación de las garantías de los derechos y los procedimientos para su protección. El artículo 143 fija mayoría absoluta de los miembros del Congreso Nacional para la aprobación, modificación, derogación o interpretación de las mismas. Así mismo, el nuevo proyecto constitucional ecuatoriano de 2008 establece el mismo planteamiento (art. 133).

En el caso de Bolivia, está garantía no se recoge en tanto la Constitución vigente $y$ el nuevo proyecto constitucional de 2007 sólo reconocen un único procedimiento legislativo ordinario, con lo cual no existen leyes orgánicas.

A pesar de que la reserva de Ley orgánica sí sirve para garantizar en mayor grado la disciplina de determinados ámbitos materiales frente a modificaciones introducidas por mayorías parlamentarias coyunturales, no es, sin embargo, una precaución suficiente, baste con citar por ejemplo las continuas reformas que sufrió la Constitución ecuatoriana previa a la del 98 , especialmente a partir de 1992, en la que el quórum de aprobación era de los dos tercios de los miembros del Congreso, o recordar las continuas enmiendas constitucionales a la Constitución brasileña de 1988, durante los años 90, destinadas a vaciar de contenido muchos derechos sociales, y cuyo quórum de aprobación era de tres quintos de los miembros del Congreso. 


\section{Referencias}

APONTE, C., (2000). "Los derechos sociales y la Constitución de 1999: ¿nuevas garantías o espejismos?. En T. Maingon (ed.). La cuestión social en la Constitución Bolivariana de Venezuela. Caracas: CENDES.

AYALA, F., (1947). Tratado de Sociologia, T. II. Buenos Aires: Ed. Losada S.A.

BISCARETTI DI RUFFIA, P., (1996). Introducción al derecho constitucional comparado. México: Fondo de Cultura Económico.

BOBBIO, N., (1981). Studi hegeliani. Torino.

BOSSUYT, M., (1993). "International Human Rights Systems: Strengths and Weakness". En K. Mahoney y P. Mahoney (eds). Human Rights in the Twenty-first century. Martinus Nijhoff: Dordrecht.

BULTÉ, J. F., (2004). "Democracla y República. Vacuidades y falsedades". En Revista Temas, № 36, Enero-marzo. La Habana

CERRONI, U., (1965). Marxy el derecho moderno. Buenos Aires: Jorge Álvarez (ed.)

DERMIZAKY, P., (2006). Derechos y garantias fundamentales. Cochabamba: Alexander. DESANTI, J.T., (1970). Fenomenología y praxis. Buenos Aires: Caldén.

DUMOND, L., (1991). Essais sur l'individualisme. Une perspectiva anthropologique sur l'idéologie moderne. Saint Amand(Cher): Ed. Senil.

DURAND, Ch., SÁNCHEZ, A.O., LOZA M., JIMÉNEZ M.D., CÓRDOBA A. y CAMPOS V., (2003). "Prospección del programa de identidad jurídica". En Política y Cultura, № 20. México.

DUSSEL, E., (1986). Etica Comunitaria. Madrid: Ediciones Paulinas.

(1994). Debate en torno a la ética del discurso de Apel. Diálogo filosófico NorteSur desde América Latina. México: Siglo XXI.

DUSSEL, E. y APEL, K. O., (1992). Fundamentación de la ética y Filasofía de la Liberación. México: Siglo XXI.

EBERHARD, C., (2003). "Derechos Humanos y diálogo intercultural. Una perspectiva antropológica". En M. Calvo García (coord.). Identidades culturales y derechos humanos. Madrid: IISJ-Dykinson. 
ENTELMAN, R., (1982). "Aportes a la formación de una epistemología jurídica en base a algunos anàlisis del funcionamiento del discurso jurídico". En W.AA. El discurso juridico. Perspectiva psicoanalitica y otros abordajes epistemológicos. Buenos Aires: Hachette.

ESPADA, J.C., (1996). Social Citizenship Rights. Oxford: St. Antony's College.

FARIÑAS DULCE, M. J., (1989). La sociología del Derecho en Mox Weber. México: Universidad Nacional Autónoma de México (UNAM).

FAYT, C. S., (2007). Evolución de los derechos sociales: del reconocimiento a la exigibilidad. Buenos Aires: FEDYE.

FERNÁNDEZ, J. A., (2005). El Tribunado; sus expresiones posibles en la crisis del actual modelo iuspublicístico. Inédito. Tesis para el grado de doctor en Ciencias Jurídicas. Facultad de Derecho. Universidad de La Habana.

FRIED, C., (1978). Right and wrong. Cambridge: Harvard University Press.

FUNKE, G., (1991). Fenomenologia: ¿metafisica o método? Caracas: Monte Avila.

GARCÍA LINERA, A., (2005). "Democracia multicultural y comunitaria". En Artículo Primero. Revista de de debate social y jurídico, año IX. № 17, Marzo. Santa Cruz de la Sierra (Bolivia): Centro de Estudios Jurídicos e Investigación Social (CEJIS)

GREGOR BARIÉ, C., (2003). Pueblos indigenas y derechos constitucionales en América Latina: un panorama. México: Ed. Instituto Indigenista latinoamericano, Comisión Nacional para el desarrollo de los pueblos indigenas; Ecuador: Editorial Abya-Yala.

HENKIN, L., (1981). The Internacional Bill of Rights: The Convenant on Civil and Political Rights. Nueva York: Columbia University Press.

HUSSERL, E., (1989). La idea de fenomenología. Cinco lecciones. México: Fondo de Cultura Económico.

KARTASHKIN, V., (1982). "Economic, Social and Cultural Rights". En K. Vasak y P. Alston (eds.). The Internacional Dimensions of Human Rights, vol. I. Paris: Greenwood Press.

KELSEN, H., (1934). Teoria General del Estado. Barcelona-Madrid-Buenos Aires: Editorial Labor, S.A.

LOPEZ, J.R., (1994). "Direito Subjetivo e Direitos Sociais: O Dilema do Judiciário no Estado Social de Direito". En J. E. Faria (ed.). Direitos Humanos, Directos Sociais e Justiça.Sao Paulo: Malheiros. 
MUÑOZ GÓMEZ, J.A., (1988). "Reflexiones sobre el uso alte rnativo del Derecho". En EI Otro Derecho, № 1. Bogotá (Colombia).

NOGUERA FERNÁNDEZ, A., (2007). Derecho y Hegemonía. Buenos Aires: Ediciones Cooperativas.

Enlace.

(2009). Constitución, plurinacionalidad y pluralismo jurídico en Bolivia. La Paz:

(2009a). "¿Derechos fundamentales, fundamentalísimos o, simplemente, derechos? El principio de indivisibilidad de los derechos en el viejo y el nuevo constitucionalismo". En Derechos y Libertades, № 21, pp. 117-147. Instituto de Derechos Humanos Bartolomé de las Casas. Madrid: Universidad Carlos III.

(2010). "Diálogos sobre la plurinacionalidad y la organización territorial del Estado en Bolivia". En Revista Española de Derecho Constitucional, № 87. Madrid: CEPC.

PALACIOS, F., (2006). "La ruptura constitucional del Estado precario: los derechos sociales en el nuevo constitucionalismo iberoamericano. La especificidad del modelo venezolano". En Àgora. Revisto de Ciencias Sociales, № 14. Valencia-España: Fundación CEPS.

PÉREZ, M., (2004). "El sistema de derechos humanos en la Constitución de 1999". En R. Viciano y L. Salamanca (eds.). El sistema político en la Constitución bolivariana de Venezuela. Caracas: Vadell Hermanos.

PEREZ-DIAZ, V., (1997). La esfera pública y la sociedad civil. Madrid: Ed. Taurus.

PINTO, M., (2004). Temas de derechos humanos. Buenos Aires: Editores del puerto.

PLAZA PELAES, M. L., (2003). "Desarrollar las diversas articulaciones regionales". En AA.VV. La descentralización que se viene. La Paz: Plural ediciones.

POPPER, K., (1981). La sociedad abierta y sus enemigos. Barcelona: Ed. Paidos.

REQUEJO, F., (2007). "Democracias plurinacionales y modelos federales. El federalismo plurinacional". En ponencia presentada en el Workshop "Democracia, ciudadania y territorialidad en sociedades plurinacionales", 14-16 de marzo. País Vasco: Instituto Internacional de Sociología Jurídica (IISJ) de Oñati.

ROBERTSON, A.H. y MERRILLS, J.G., (1989). Human Rights in the world. Manchester: Manchester University Press. 
RUIZ, A., (1991). "La categoría del sujeto de Derecho". En E. Marí, R. Entelman, C. M. Cárcova y A. Ruiz A. Materiales para una teoría crítica del Derecho. Buenos Aires: Abedelo-Perrot.

RUSSERL, E., (1989). La idea de fenomenología. Cinco lecciones. México: Fondo de Cultura Económico.

SCHERER-WARREN, I.y KRISCHKE, P.J., (1987). Uma Revoluçao no Cotidiano. Sao Paulo SHRÖDINGER, E., (1958). Mind and matter. Cambridge University Press.

VAN DE LUYTGAARDEN, E., (1993). Introduction to the theory of Human Rights Law. Utrecht: Universidad de Utrecht.

VICIANO, R. y MARTÍNEZ, R., (2005). "EI proceso constituyente venezolano en el marco del nuevo constitucionalismo latinoamericano". En Àgora. Revista de Ciencias Sociales, № 13, pp. 55-68. Valencia. España: Fundación CEPS.

VIGEVANI, T., (1989). "Movimientos Sociais na Trasiçao Brasileira: A Dificultade de Elaboraçao de Projeto". En Lua Nova: Revista de Cultura e Politica, № 17. Sao Paulo.

VIROUX, A., (1964). Léxico de Sociología. Barcelona: Estela. 